\title{
Virginia Nursery and Greenhouse Grower Survey of Best Management Practices
}

\author{
Rachel Mack ${ }^{1}$, James S. Owen ${ }^{2,4}$, Alex X. Niemiera ${ }^{3}$, and \\ Joyce Latimer ${ }^{3}$
}

ADDITIONAL INDEX WORDs. water, fertilizer, runoff, barriers to adoption

Summary. A survey, focusing on the use of irrigation and fertilization best management practices (BMPs), was designed and released to Virginia nursery and greenhouse growers. The objectives of the survey were to determine the most widely used BMPs, assess the reasons for their use, and identify barriers to BMP adoption. The survey was distributed in person, via e-mail attachment, or link to 357 Virginia growers in 2016 with 60 respondents. Survey results demonstrate that the most widely used BMPs in Virginia included irrigation scheduling, integrated pest management (IPM) implementation, altering irrigation practices to optimize irrigation efficiency, controlled-release fertilizer (CRF) use, and plant need-based watering. Respondents selected environmental/resource savings as one of the most cited reasons behind BMP use for water, fertilizer, and runoff management. Cost was the most cited barrier to BMP adoption for all BMPs. Fertilizer management BMP implementation was primarily an economic decision. The value of determining the most widely used BMPs and impediments to BMP adoption is that we can 1) communicate this information to growers who currently do not employ BMPs to encourage BMP adoption and 2) subsequently inform the regulatory community of BMP use. Increased BMP use can boost the potential for mitigation of agricultural nutrient and sediment runoff into impaired waterways, including the Chesapeake Bay, and help growers increase efficiency of operation inputs, such as water and fertilizer resources, while potentially saving money.

$\mathrm{N}$ egative environmental impacts resulting from nursery and greenhouse production practices are major concerns to producers in the mid-Atlantic and southeast United States because of potential future regulation impacting crop production and profitability. Contaminants (such as fertilizers, agrichemicals, and sediment) leaving an operation via runoff water from an agricultural production site are considered nonpoint source pollution and can contribute to the impairment of waterways downstream (Majsztrik and Lea-Cox, 2013). Nonpoint source water pollution can be, in part, mitigated by the use of BMPs. BMPs are

\footnotetext{
Department of Horticulture, Virginia Tech, Blacksburg, VA 24061

Funded in part by the Virginia Nursery \& Landscape Association, Virginia Agricultural Council, Virginia Agricultural Experiment Station and the Hatch Program of the National Institute of Food and Agriculture, U.S. Department of Agriculture, including work under award Specialty Crops Research Initiative project 2014-51181-22372 (Clean WateR ${ }^{3}$ ).

${ }^{1}$ Graduate Student.

${ }^{2}$ Associate Professor.

${ }^{3}$ Professor.
}

${ }^{4}$ Corresponding author. E-mail: jim.owen@vt.edu. doi: 10.21273/HORTTECH03664-17 defined as "schedules of activities, prohibitions, maintenance procedures, and structural or other management practices found to be the most effective and practicable to prevent or reduce the discharge of pollutants to the air or waters of the U.S. BMPs also include operating procedures, and practices to control site runoff, ground water contamination, spillage or leaks, sludge or waste disposal, or drainage from raw material storage" (Bilderback et al., 2013). The compendium of BMPs that can be used by growers to reduce runoff, and increase fertilizer and water use efficiency, while also protecting the surrounding ecosystem is Best Management Practices Guide: Guide for Producing Nursery Crops (Bilderback et al., 2013).

Agriculture, including nursery and greenhouse operations, is considered a leading source of nonpoint source water pollution (U.S. Environmental Protection Agency, 2005). To ensure human safety and protect the environment, the Environmental Protection Agency issued a total maximum daily load (TMDL) establishing limits to the amount of sediment and nutrients that can be discharged into tributaries of the Chesapeake Bay (U.S. Environmental Protection Agency, 2010, 2015). The Commonwealth of Virginia and other states in Chesapeake Bay watershed are responsible for reducing nutrients such as nitrogen $(\mathrm{N})$ and phosphorus $(\mathrm{P})$, and sediment from point and nonpoint sources such as municipal wastewater treatment, agriculture, and urban stormwater. BMPs used by agriculture producers are important tools to meet clean water goals, and voluntary adoption of these practices by the nursery and greenhouse industry is needed to show a good faith attempt to meet these goals and to practice good land stewardship. Knowledge and communication of the most widely used BMPs in Virginia, and the challenges and benefits associated with their use, can encourage grower adoption of BMPs throughout the midAtlantic and southeast United States and inform policymakers thereby increasing the number of growers assisting in meeting the demands associated with regulatory pressure to reduce sediment and nutrient nonpoint discharge from specialty crop operations.

Virginia's nursery and floriculture crop sales, which exceed \$213 million annually, are a significant economic component of the estimated $\$ 1.42$ billion of ornamental crops sold in the mid-Atlantic United States (U.S. Department of Agriculture, 2012). Thus, assessing the impact of BMPs on production as well as water quality is important. Although the Virginia greenhouse industry has been profiled via a survey including regulatory compliance, and water and fertilizer management (Scoggins et al., 2003, 2004), a survey of nursery and greenhouse BMP use in Virginia has not been conducted. The objectives of this study were to survey Virginia nursery and greenhouse growers to determine 1) the most widely used BMPs, 2) the reasons behind BMP use, and 3 ) the barriers

\begin{tabular}{llll}
\hline $\begin{array}{l}\text { Units } \\
\text { To convert U.S. to SI, } \\
\text { multiply by }\end{array}$ & U.S. unit & SI unit & $\begin{array}{l}\text { To convert SI to U.S., } \\
\text { multiply by }\end{array}$ \\
\hline 0.4047 & acre(s) & ha & 2.4711
\end{tabular}


to BMP adoption. Findings will be communicated to nursery and greenhouse growers via Extension and trade publications with the goal of increasing grower awareness and adoption of BMPs.

\section{Materials and methods}

EXPLORATORY SURVEY. An institutional review board (IRB)-approved exploratory survey (ES) was developed to test objectivity of potential survey questions and to determine grower perceptions of BMPs (Mack, 2016). The ES asked growers for general information about BMPs and was conducted in person or by phone. The ES was conducted in an interview format, and growers were not limited by time.

The ES administration process included the use of a phone contact script, an e-mail contact script, a basic information sheet about BMPs and the study, a consent form, and the ES itself. Thirteen Virginia growers were initially contacted in 2015 based on their expected knowledge and use of BMPs, as recommended by Virginia Tech faculty. All indicated a willingness to participate in the ES. However, because of extenuating nursery/ greenhouse business schedules, only five respondents completed the ES.

A consent form detailing the ES and its risks was signed by participating growers before completion of the interviews. The ES information sheet, given to respondents before taking part in the pilot survey, briefly explained the purpose of the research and included examples of BMPs so respondents would answer interview questions based on a general knowledge of BMP concepts. Grower responses to the ES were recorded, with codes used to protect respondent confidentiality.

The 15-question ES asked respondents to identify BMPs used at the growing operation, the type of the growing operation, gross sales, and information sources used to make decisions regarding BMP implementation. Management strategies and infrastructure BMPs that were used to maximize water and fertilizer use and reduce leaching were the primary focus of the survey. Questions were asked to determine BMPs used in Virginia, probe barriers to their adoption, and delineate reasons behind BMP-related decisions. Grower perception of BMPs, such as whether growers identified certain practices as BMPs, was evaluated by the ES. Cost-effectiveness of BMPs was included to identify BMPs that provide useful benefits in cost reduction and production efficiency. The ES also covered water management-related issues that growers reported to investigators.

Principal survey. An IRBapproved survey [IRB no. 15-720 (Mack, 2016)] on BMP use was disseminated to 357 Virginia nursery and greenhouse growers via e-mail attachment, Qualtrics (Provo, UT) link, or in person at the mid-Atlantic Nursery Trade Show (Baltimore, MD) from 6 Jan. 2016. The survey consisted of 22 questions (Table 1), and an e-mail reminder was used to encourage participation. Operations qualified if they were a container nursery, field nursery, or greenhouse with at least one location in Virginia. As an incentive to participate in the survey, a $\mathrm{pH} / \mathrm{EC}$ meter was offered as a prize to one respondent who completed the survey via lottery. The survey was closed on 22 Feb. 2016. Completing the survey constituted consent for information to be used in research. Any identifying information was kept confidential.

To understand which BMPs were most widely used and why, respondents were asked about BMPs that were commonly identified in the ES and included questions on the most widely used BMPs, respondents' perceptions of BMPs, and their perceived benefits and drawbacks of BMP use. The survey instrument employed a combination of questions including multiple choice, fill-in dialog box, and Likert scale (1 to 10). Survey questions were based on BMPs found in a literature search and through the ES. The survey provided a definition of a BMP and an example of a BMP in the introduction. Consent to participate in the study was included on the landing (first) page in the survey tool. Growers were questioned about their use and familiarity with BMPs. Respondents who did not have a baseline knowledge of BMPs were excluded from the analysis. Growers with multiple locations were asked to answer questions based on their Virginia location(s).

Analysis. The use of each of 10 surveyed BMPs was tested individually using Fisher's exact test, and operation types (nursery vs. greenhouse) were compared. No differences in BMP use among greenhouses, nurseries, and 50/50 (nursery/greenhouse) groups for each respective BMP were noted, with probability values ranging from 0.22 to 1 ; thus, data were pooled for these three groups.

\section{Results and discussion}

ExplORATORY SURVEY. Recruitment of growers who currently use BMPs was critical to the survey to obtain detailed BMP use information and insights into guide the development of the principal survey. The ES respondents included three outdoor container nurseries, one greenhouse, and one greenhouse/nursery combination. Operation size ranged from 25 to 400 acres. All growers used BMPs. Gross sales of participating operations were $\$ 5$ million to $\$ 10$ million. The most widely used BMPs were IPM, CRFs, and water recapture, including practices such as using ponds to recapture water (Table 2). One grower grouped plants by water needs (Table 2). Water management practices for optimizing irrigation efficiency were used by four respondents. Water management practices included cyclic irrigation, measuring leaching fraction, and timing irrigation according to weather conditions (wind speed, temperature, and relative humidity). Irrigation scheduling was primarily determined by grower experience and based on plant need. In further discussion with the growers during the ES, concerns related both to the quality and quantity of water available for use were indicated, with greater focus on water collected and used on-site compared with water from runoff that may leave the nursery or greenhouse site. Fertilizer was applied using a combination of both $\mathrm{CRF}$ and liquid form by four of the operations, whereas one grower used liquid fertilizer only. Fertilizer decisions were largely made based on plant need. Most respondents treated their water with chlorine (data not presented). Respondents initially underreported BMP use, requiring further questioning to obtain a complete list of BMPs used at each site. Some respondents reported that they saved money or resources with BMP use. Respondents who mentioned BMP implementation costs were unable to provide cost estimates because of the complex and often interwoven nature of cost inputs such as time, 


\section{Research Reports}

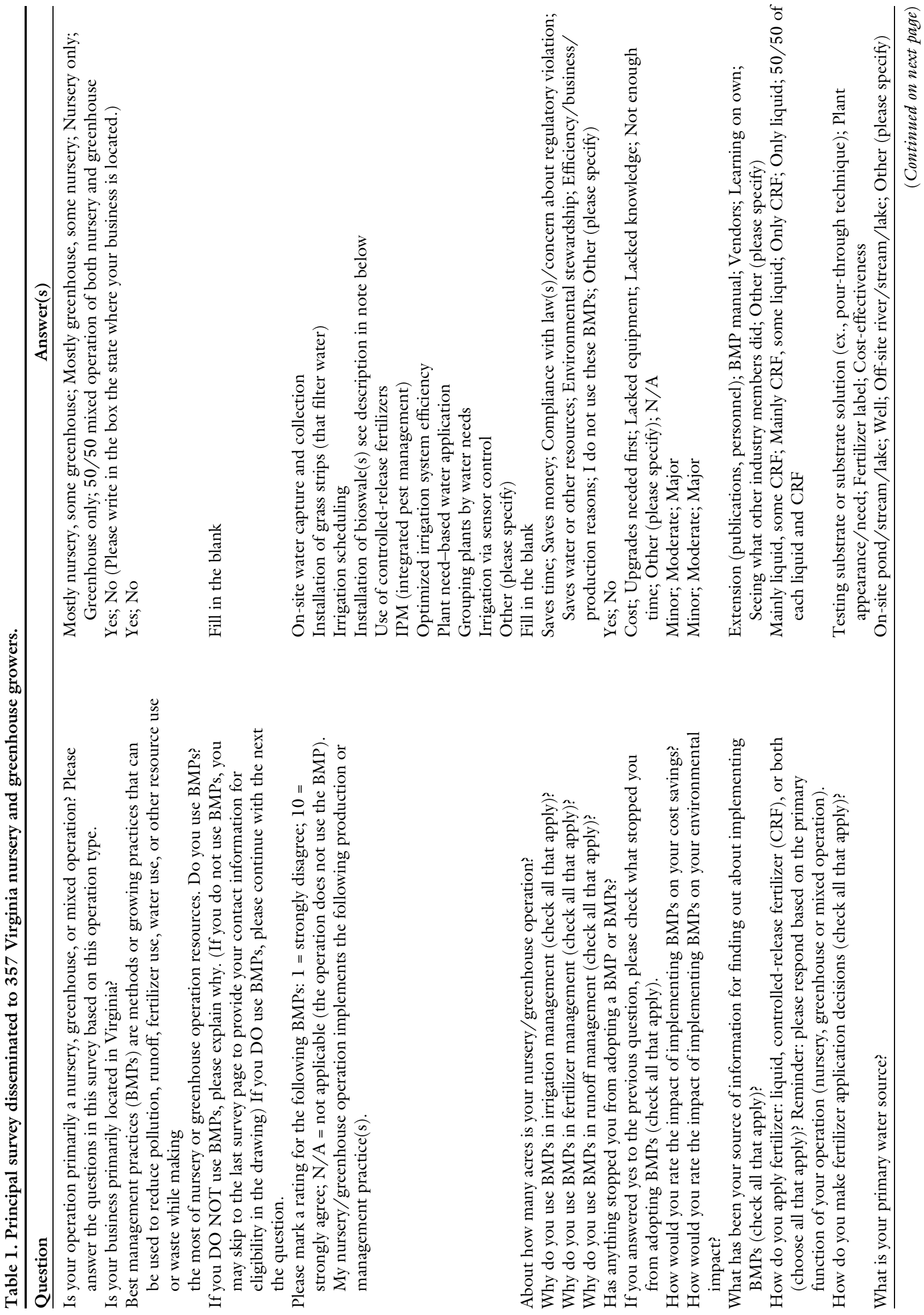




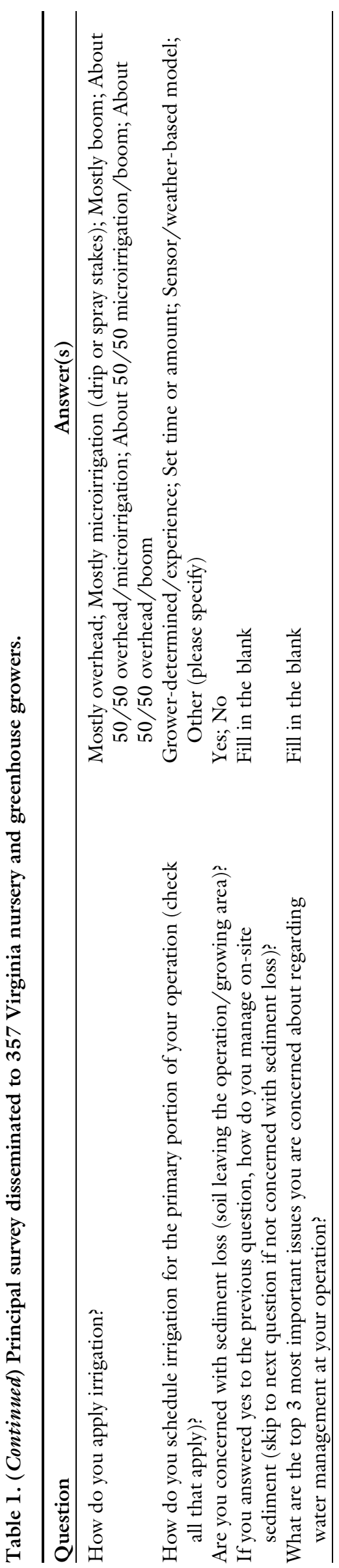

material, portion of labor devoted to BMPs, experience level of personnel, and salaries of those devoted to BMPs. The information from the ES was used to inform the principal survey.

Principal survey. Sixty growers responded to the survey, resulting in a $17 \%$ response rate. This response rate has a $10 \%$ margin of error for drawing conclusions about the Virginia grower population as a whole; however, from a qualitative standpoint, this response rate is valid in contributing to a wider understanding of the practice of BMP use (Northcote, 2012). Participating respondents had greenhouse and field or container nursery operations which ranged in size from 0.33 to 900 acres. Median size of participating operations was 7.5 acres, and the mean size was 89 acres. Operation types consisted of those that were solely or mostly nursery (61\%), solely or mostly greenhouse $(27 \%)$, and about half-greenhouse and halfnursery (13\%). All participating growers had operations in Virginia.

All 60 survey respondents reported using BMPs. The most highly ranked (based on a Likert scale) and most frequently used BMPs were irrigation scheduling, IPM, optimized irrigation efficiency, plant need-based watering, grouping plants by water needs, use of CRFs, and on-site water capture and collection (Table 3 ).

Overall, the most cited reasons for grower BMP use for irrigation, fertilizer, or runoff management were resource savings $(86 \%)$, saving money $(77 \%)$, and environmental stewardship (84\%), respectively (data not presented). Environmental stewardship was a common reason for respondent use of BMPs for water, fertilizer, and runoff management, indicating that growers are concerned about the environmental impacts of production practices.

Best management practices can aid specialty crop producers in increasing production efficiency while reducing nutrient runoff output (Bilderback et al., 2013), although some BMPs may reduce profitability, such as when deficit irrigation reduces crop size or increases time to market; for this reason, such BMPs are unlikely to be adopted for costeffectiveness alone. Surveys (Fain et al., 2000; Garber et al., 2002) have found that container-grown plant nurseries can be proactive in decreasing negative environmental impacts during production by implementing BMPs. Fain et al. (2000) found that Alabama growers were concerned with environmental impacts and were willing to make changes in production practices, including the installation of BMPs. Improved production efficiency and cost-effectiveness are reported benefits of BMP use (Yeager et al., 2010). The extent of a grower's use of a BMP may not only be site specific but also region specific (Schoene et al., 2006), which was why concentrating our survey on the nursery and greenhouse industry within a defined geographic area was important in gaining an understanding of which BMPs were being used in Virginia. However, information from our survey on the reasons growers use BMPs may be applicable to areas with a similar geography, climate, and soil. The overall findings related to the motives of BMP use (to be discussed) can support BMP adoption in other regions.

IRRIGATION MANAGEMENT. Respondents had multiple reasons for their use of BMPs in irrigation management, including developing water or other resource savings, environmental stewardship, and efficiency, business, or production reasons (Table 4). Virginia growers who noted "other" reasons explained their operations did not require irrigation as they relied on rainfall. Water sources for irrigation included well water $(50 \%)$; on-site pond, streams, or lake $(37 \%)$; and other (12\%). Growers who used other water sources reported combinations of water source types. Only one grower used an off-site stream or lake.

In a characterization of irrigation method, Virginia growers applied irrigation via overhead sprinklers $(45 \%)$, overhead-microirrigation combination $(27 \%)$, or microirrigation (20\%). Only 6\% used mostly boom irrigation. Irrigation scheduling was grower-determined or based on grower experience $(90 \%)$, with some growers also employing irrigation scheduling based on a set time or irrigation amount (27\%). Only one grower used a sensor or weatherbased model for irrigation scheduling. On a Likert scale, the use of 
Table 2. Exploratory survey of best management practices (BMPs) administered to five operations that self-identified as follows: one greenhouse, three nurseries, and one combination nursery/greenhouse $(n=5)$. Respondents were asked open-ended questions about BMP use.

\begin{tabular}{lc}
\hline BMP & Respondents (no.) \\
\hline What BMPs do you use? & 5 \\
Integrated pest management & 5 \\
Controlled-release fertilizers & 5 \\
Pond(s) to recapture water & 4 \\
Grass strips & 4 \\
Water management practices & 4 \\
Drip irrigation & 3 \\
Recycling water & 2 \\
Filter socks & 1 \\
Grouping plants with similar needs & \\
How do you make fertilizer decisions? & 4 \\
Plant need & 3 \\
Testing: EC/pH & 1 \\
Based on timing of crop finishing & 1 \\
Past experience & 1 \\
Fertilizer label & 1 \\
Cost-effectiveness & \\
How do you schedule irrigation (plant need, set schedule, and sensors)? & 3 \\
Grower-determined or plant need & 1 \\
Computerized & 1 \\
Cyclical/on a timer & 1 \\
Sensors & \\
\hline
\end{tabular}

Table 3. Average rating and number of responding nursery and greenhouse growers using selected best management practices (BMPs) on a survey of BMPs for Virginia container nursery and greenhouse producers $(n=60)$ for Likert scale question: My nursery/greenhouse operation implements the following production or management practice(s).

\begin{tabular}{lcc}
\hline $\mathbf{B M P}^{\mathbf{z}}$ & Avg rating $(\mathbf{1}$ to $\mathbf{1 0}$ scale) & Respondents (no.) $^{\mathbf{y}}$ \\
\hline Irrigation scheduling & 9.0 & 48 \\
Integrated pest management & 8.5 & 53 \\
Optimized irrigation efficiency & 8.4 & 49 \\
Plant need based watering & 8.3 & 51 \\
Grouping plants-water need & 8.1 & 52 \\
Controlled-release fertilizer & 8.0 & 52 \\
Water capture/collection & 7.5 & 51 \\
\hline
\end{tabular}

${ }^{\mathrm{z}} \mathrm{BMPs}$ presented in this table were a result of responses from more than $80 \%$ of respondents. ${ }^{\mathrm{y}} 1=$ strongly disagree and $10=$ strongly agree.

Table 4. Reasons survey respondents use irrigation management practices $(n=56)$ when asked "Why do you use best management practices in irrigation management (check all that apply)?”

\section{Reason for use}

Saves water or other resources

Environmental stewardship

Efficiency/business/production reasons

Saves money

Saves time

Legal compliance/regulatory violation concern

${ }^{\mathrm{z}}$ Percentage of 56 respondents who identified this reason for using irrigation management best management practices. sensor-controlled irrigation was not highly ranked by respondents $(4.5 / 10)$, indicating that sensors are not widely used among responding Virginia growers. Irrigation management is directly connected to fertilizer management because fertilizer is generally leached during an irrigation event regardless of irrigation and fertilizer application method (CRF or applied as a liquid through the irrigation system). The impact of applied fertilizers exiting the growing area is especially relevant for growers who apply fertilizer through their irrigation lines (i.e., liquid feed) in which case fertilizer may be applied to containers and the spaces in between containers (Majsztrik et al., 2011). Although irrigation and fertilization methods vary in their efficiency of use, all current irrigation and fertilization methods result in fertilizer exiting containers and the growing area. Thus, emphasis should be commensurately placed on BMPs addressing collection of production area runoff.

Fertilizer management. Monetary savings, efficiency, business, or production reasons and environmental stewardship were the most cited reasons $(\geq 70 \%)$ that respondents reported using BMPs in fertilizer management (Table 5). While the most selected reason for BMP use for fertilizer management was money savings, environmental stewardship ranked as the third most important reason. As business people who also interact with the environment daily, greenhouse and nursery operators are cognizant of the importance of valuing both environmental resources, such as the water and land needed to produce their products, and the economic considerations involved in balancing production efficiency with water quality.

Less-cited reasons that explained grower use of fertilizer management BMPs included time savings, water or other resource savings, and regulatory compliance (Table 5). Fertilizer application methods varied among growers. Most respondents used a combination of CRF and liquid fertilizer $(60 \%)$, whereas some growers used only CRF (31\%). Fertilizer application decisions were made based on plant appearance/need (87\%), testing substrate solution $(46 \%)$, referencing the fertilizer label $(42 \%)$, and fertilizer cost-effectiveness (21\%). Therefore, 
Table 5. Reasons principal survey respondents $(n=56)$ use fertilizer management practices when asked "Why do you use best management practices in fertilizer management (check all that apply)?"

\begin{tabular}{lc}
\hline Reason for use & Respondents $(\%)^{\mathbf{z}}$ \\
\hline Saves money & 77 \\
Efficiency/business/production reasons & 71 \\
Environmental stewardship & 70 \\
Saves time & 48 \\
Saves water or other resources & 41 \\
Legal compliance/regulatory violation concern & 30 \\
\hline
\end{tabular}

${ }^{z}$ Percentage of 56 respondents who identified this reason for using fertilizer management best management practices.

although monetary savings was a primary reason supporting BMP use for fertilizer management, growers placed highest value on fertilizer application decisions that enhanced plant appearance or met plant needs. This is likely a response for growers to produce high-quality plants in the shortest time possible, the ultimate objective of all profitable greenhouse and nursery growers.

RuNOFF MANAgEMENT. Use of on-site water capture and collection $(77 \%)$ in our survey was higher than the results of the use of the same BMP in other surveys in Georgia [48\% (Garber et al., 2002)] and Florida [34\% (Schoene et al., 2006)] (data not presented). The responses in our survey could have been influenced by a recent drought as some growers had switched to water collection as a means to ensure an adequate water supply. Growers reported that environmental stewardship $(84 \%)$, water or resource savings $(65 \%)$, and efficiency, business, or production reasons $(45 \%)$ explained their BMP use for managing fertilizer runoff (fertilizer exiting growing area). Less-cited reasons for using runoff management BMPs were regulatory concerns $(35 \%)$ or savings in money $(27 \%)$ or time $(16 \%)$. Because nursery and greenhouse crop growers have a primary reliance on environmental aspects such as ample water supply and good water quality, the respondents' high concern for environmental stewardship and resource savings relative to BMP use is understandable and is consistent with the fact that these environmental aspects are more highly rated than the regulatory or financial aspects of BMP use. These environmentally driven motives for BMP use can be used in communicating BMP use to new growers or growers who currently do not use BMPs.
Nearly three-fourths of respondents were not concerned about sediment loss from growing areas $(73 \%)$; the minority $(27 \%)$ that expressed concern for sediment loss supplied comments on their runoff management methods. Write-in comments noted that the methods growers used to manage on-site sediment included maintaining vegetated grassed areas and ditches, sediment ponds, grading, gravel filters, cover crops, and drainage swales. These comments suggest that some growers are taking action to reduce nutrient and sediment runoff from container-grown plant production areas. The write-in comments implied that at least one respondent managed a field-grown nursery. The study, for brevity's sake, did not collect data on nursery type (container vs. field), and therefore, we cannot make conclusions related to field production. In a study of container runoff in six states (including Virginia), Yeager et al. (1993) stressed the need for implementation of BMPs to decrease runoff nutrient levels that, in some cases, were found to be in excess of federal drinking water standards (a metric often used in studies of runoff). Runoff mitigation, including protecting water quality and reducing runoff amount, is therefore a major topic of concern for scientists and for growers who wish to implement BMPs to reduce runoff to meet upcoming TMDL goals within watersheds containing impaired waterways.

BARRIERS TO BMP ADOPTION. Growers were questioned on whether they had encountered barriers to BMP adoption. The majority of respondents $(71 \%)$ indicated they had not encountered barriers. The $29 \%$ of respondents who answered affirmatively were asked to explain what impeded them from adopting BMPs.
Respondent reasons for not adopting BMPs included cost $(67 \%)$, the need for upgrades to be made first (53\%), lack of equipment (33\%), not enough time $(33 \%)$, and lack of knowledge $(27 \%)$. In an interpretation of these data, growers are apparently more likely to implement easy-to-install or low-cost BMPs. We hypothesize that when growers implement a BMP that requires more than minimal inputs of cost, time, equipment, or knowledge, the reason is likely due to necessity.

BMP IMPACTS ON OPERATION AND ENVIRONMENT. Respondents were asked to rate the effect of BMP implementation on their cost savings and environmental impacts. Respondents reported that BMPs had minor (40\%) to moderate $(50 \%)$ impacts on cost savings. Only $10 \%$ said that BMPs had a major effect on cost savings. The effect of implementation of BMPs on environmental impact was rated by respondents as moderate $(53 \%)$, major $(35 \%)$, or minor $(12 \%)$, indicating that most responding growers believe that BMP use has more than a minimal effect on environmental impact.

RESPONDENT COMMENTS. The survey included a fill-in-the-box section that encouraged participating growers to list the top water management issues affecting their specific growing operations. Most responses included water availability or access, water quality, and water use or waste. Reasons behind these concerns likely vary by individual operation. Bilderback (2002) suggested that growers may be concerned about water waste and may benefit from the use of shut off valves in individual sprinklers to prevent water waste on the removal of a crop from a particular irrigation zone. Schoene et al. (2006) noted that growers who use overhead irrigation may be concerned about the effect of water quality on plant appearance.

EDUCATION. Respondents reported that their sources of BMP information included learning on their own $(81 \%)$, observing BMP use by other industry personnel (62\%), Extension publications $(60 \%)$, vendors (21\%), a BMP manual (13\%), and other $(12 \%)$. Because most respondents receive their information by learning on their own or observing BMP use by others in the industry, efforts to increase BMP use should be 
conducted with these sources in mind. Communication of these results via grower-to-grower networks, Cooperative Extension and trade publications can educate growers on BMP use in ornamental production and help encourage BMP adoption by growers who do not use or have limited use of BMPs. Communicating this information regarding BMPs will empower growers to make better selections of the BMPs most appropriate for their respective production practices.

\section{Conclusions}

BMPs were used by $100 \%$ of survey respondents, indicating that they are in common use in Virginia nursery and greenhouse commercial production operations. Furthermore, BMPs are used selectively in the industry to minimize and increase efficiency in water and fertilizer use and to reduce production costs. Survey results indicate that growers are cognizant of both business and environmental issues and concerns. Based on survey results, the Virginia industry best learns from other industry growers, learning on their own, and through Cooperative Extension. Therefore, it is likely that focusing on BMPs that are currently being implemented by growers can lead to increased BMP adoption, resulting in a decreased amount of nutrients and sediment runoff into impaired waterways. In addition, growers can make more efficient use of inputs, such as fresh water, with increased BMP use. Increasingly strict water quality standards cast BMPs as both fundamentally relevant and viable tools to empower growers wishing to balance the often competing issues of environmental stewardship and operation productivity.

Further research is needed to quantitatively determine the efficacy of the numerous BMPs prescribed for the greenhouse and nursery industry. While there is a general consensus of the use of the BMPs surveyed, there is a need to link specific BMPs with the associated relevant peer-reviewed publications within compendiums of BMP practices such as the Southern Nursery Association Best Management Practices Guide thus validating them for the growers and regulators. Such validation could showcase the potential positive impacts of BMP use on the environment without decreasing specialty crop profitability. With increasing demands on both land and water resources, both environmental and production goals should be considerations when changes in practice are considered. As BMPs are the tools to minimize production impacts on the environment, BMP use will likely increase in the future within specialty crop production.

\section{Literature cited}

Bilderback, T. 2002. Water management is key in reducing nutrient runoff from container nurseries. HortTechnology 12:541-544.

Bilderback, T., C. Boyer, M. Chappell, G. Fain, D. Fare, B.E. Jackson, J. Lea-Cox, A.V. LeBude, A. Niemiera, J. Owen, J. Ruter, K. Tilt, S. Warren, S. White, T. Whitwell, R. Wright, and T. Yeager. 2013. Best management practices: Guide for producing nursery crops. 3rd ed. Southern Nursery Assn., Acworth, GA.

Fain, G.B., C.H. Gilliam, K.M. Tilt, J.W. Olive, and B. Wallace. 2000. Survey of best management practices in container production nurseries. J. Environ. Hort. 18:142-144.

Garber, M.P., J.M. Ruter, J.T. Midcap, and K. Bondari. 2002. Survey of container nursery irrigation practices in Georgia. HortTechnology 12:727-731.

Mack, R. 2016. Best management practice use and efficacy for the Virginia nursery and greenhouse industry. Virginia Tech, Blacksburg, MS Thesis.

Majsztrik, J. and J.D. Lea-Cox. 2013. Water quality regulations in the Chesapeake Bay: Working to more precisely estimate nutrient loading rates and incentivize best management practices in the nursery and greenhouse industry. HortScience 48:1097-1102.

Majsztrik, J., A.G. Ristvey, and J.D. Lea-Cox. 2011. Water and nutrient management in the production of container-grown ornamentals. Hort. Rev. 38:253-297.

Northcote, M.T. 2012. Selecting criteria to evaluate qualitative research. 21 Jan. 2017. <http://research.avondale.edu. au $/$ cgi/viewcontent.cgi? article $=1038 \&$ context=edu_papers $>$.

Schoene, G., T. Yeager, and D. Haman. 2006. Survey of container nursery irrigation practices in west-central Florida: An educational opportunity. HortTechnology 16:682-685.

Scoggins, H.L., J.G. Latimer, and V.T. Barden. 2003. Profile of the Virginia commercial greenhouse industry. HortTechnology 13:526-531.

Scoggins, H.L., J.G. Latimer, and V.T. Barden. 2004. The Virginia commercial greenhouse industry-current practices and future needs assessment. HortTechnology 14:109-114.

U.S. Department of Agriculture. 2012. Virginia nursery and floriculture totals. 2 Jan 2017. <https://quickstats.nass.usda. gov $/>$.

U.S. Environmental Protection Agency. 2005. Protecting water quality from agricultural runoff. 20 Feb. 2015. <http:// water.epa.gov/polwaste/nps/upload/ Ag_Runoff_Fact_Sheet.pdf $>$.

U.S. Environmental Protection Agency. 2010. Chesapeake Bay total maximum daily load for nitrogen, phosphorus, and sediment. Executive Summary. 31 Jan. 2015. <http://www.epa.gov/reg3wapd/ pdf/pdf_chesbay/FinalBayTMDL/ CBayFinalTMDLExecSumSection lthrough3_final.pdf $>$.

U.S. Environmental Protection Agency. 2015. Chesapeake Bay TMDL. 20 Feb. 2015 . <http://www.epa.gov/ reg3wapd/tmdl/ChesapeakeBay/index. html>.

Yeager, T., J. Million, C. Larsen, and B. Stamps. 2010. Florida nursery best management practices: Past, present, and future. HortTechnology 20:82-88.

Yeager, T., R. Wright, D. Fare, J. Gilliam, T. Bilderback, and R. Zondag. 1993. Six state survey of container nursery nitrate nitrogen runoff. J. Environ. Hort. 11:206208. 